\title{
Demographic shift disproportionately increases cancer burden in an aging nation: current and expected incidence and mortality in Hungary up to 2030
}

This article was published in the following Dove Press journal: Clinical Epidemiology

\author{
Otília Menyhárt ${ }^{1,2}$ \\ János T Fekete ${ }^{2}$ \\ Balázs Győrffy ${ }^{1,2}$ \\ 'MTA TTK Lendület Cancer \\ Biomarker Research Group, Institute \\ of Enzymology, Hungarian Academy \\ of Sciences, Budapest, Hungary; ${ }^{2} 2$ nd \\ Department of Pediatrics, Semmelweis \\ University, Budapest, Hungary
}

\begin{abstract}
Background: Population aging is a common demographic pattern in developed countries, and aging increases the risk of cancer. The disproportionately high cancer burden, as a consequence, is especially pronounced in Central and Eastern European countries, including Hungary.

Methods: We summarized current and projected future cancer incidences and mortalities utilizing data from the last two decades. Predictions are based on cancer incidence and mortality collected between 1996 and 2015 in Hungary. In addition to the crude rates, data were age standardized to the European standard population (ESP) of 2013, ESP of 1976, and local census of 2011.

Results: The lifetime probability of developing cancer and cancer-related mortality has already reached $56.9 \%$ and $27.6 \%$ in men, respectively, and $51.9 \%$ and $21.7 \%$ in women. Between 2016 and 2030 , the total population is expected to shrink by $6 \%$, while the number of 60 -year olds and above will grow by $18 \%$. This will lead to a $35 \%$ increase in cancer incidence and $30 \%$ increase in cancer death among 65-85-year olds. Joinpoint regression identified the period 2007-2015 as starting point for this coming increase in new cases. In women, lung and breast cancer will increase yearly by $1.9 \%$ and $1.7 \%$, respectively, between 2016 and 2030 , while in men, the prostate and colorectal cancer rates will increase yearly by $3.6 \%$ and $2.1 \%$.

Conclusion: In the aging population of Hungary, cancer incidence will increase considerably over previous projections. Although a large portion of the most rapidly rising cancers are avoidable by implementing public health programs, a substantial portion remains inevitably incurable.
\end{abstract}

Keywords: cancer, biostatistics, aging, lung cancer, colon cancer, breast cancer, prostate cancer

\section{Introduction}

Projecting in advance the incidence and mortality of diseases is crucial to identify major focal points for research and for preventive health programs, and it helps to limit shortfalls in diagnostic procedures and interventions. Resources need to be prioritized for funding and for improvements in quality of life. These considerations are especially important for countries with high cancer rates and with rapid, ongoing population transformations.

Population aging is a common demographic pattern across most developed countries. With an average fertility of 1.6 children per woman and a life expectancy of 77 years, Europe has the highest proportion of population aged 60 years or over $(24 \%)$. The total number of inhabitants is projected to be below the 2015 level in $2050 .{ }^{1}$ Inhabited
Correspondence: Balázs Győrffy

Lendület Cancer Biomarker Research

Group, MTA TTK, Institute of

Enzymology, Magyar tudósok körútja 2,

$\mathrm{H}-\mathrm{I}$ I I7, Budapest, Hungary

Tel +36 $305 I 42822$

Email gyorffy.balazs@ttk.mta.hu 
by only $10 \%$ of the total world population, Europe is overwhelmed by $24.4 \%$ of the global cancer incidence and $21.5 \%$ of cancer-related mortality. ${ }^{2}$ The majority of Central, Eastern, and Southern Europe, with fertility rates at or below 1.5, is experiencing an even more accelerated demographic change.

The epidemiological cancer burden of Hungary is among the highest in Europe ${ }^{3}$ including the highest cancer-related overall mortality in men (estimated age-standardized rates [ASRs]: 306.3 in Hungary vs. 222.5 in Europe) and the third highest mortality among women (163.6 vs. 128.8 in Europe). Among 40 European countries, the incidence of lung and bronchus cancer (LC), colon and rectum cancer (CRC), and oral cavity-pharynx cancers is highest in Hungary among both males and females. ${ }^{1,3}$ Neighboring countries, such as the Czech Republic, Slovenia, Slovakia, Croatia, and Serbia, experience cancer incidences comparable to Hungary. ${ }^{3,4}$ At the same time, Hungary has a traditionally high autopsy rate of $37 \%$ compared to only $15 \%$ for other European Union (EU) members according to the WHO European Health Information Gateway (or to less than $1 \%$ in the UK). ${ }^{5}$ The National Cancer Registry covers $100 \%$ of the population hospitals are required by law to report cancer-related data to the National Cancer Registry quarterly [24/1999. (VII. 6.) EüM] (https://uj.jogtar.hu/\#doc/db/1/id/99900024.EUM/), followed by data verification performed by the Registry, which usually takes up to 3 years. The combination of outstandingly reliable medical data in an aging country with high cancer burden makes Hungary a good model to predict trends in cancer epidemiology for countries with similar predicaments. Our model offers extrapolations, especially for the Central and Eastern European regions, where demography and cancer burden are similar across countries. ${ }^{3}$

Comparing cancer incidence and mortality patterns across countries or over time within a population requires standardization. The ASR is a weighted mean of age specific rates. The weights are taken from a standard population (World Standard Population or European Standard Population [ESP]), ${ }^{6}$ frequently expressed per 100,000 person-years. While ASR approximates the population's risk of being diagnosed with cancer, it does not incorporate the effect of demographic change on cancer burden and does not provide clear projections of the local patterns within a given country.

Current fertility rates are projected to shift the age distribution further in developed countries. Thus, cancer incidence rates are expected to markedly increase. Here, our aim is to use epidemiologic data available in Hungary to provide straightforward, site-specific predictions for all major cancers, serving as a reference for countries struggling with similar rapid demographic changes coupled with high cancer rates. To assess the impact of changes in the population age structure and current risk trends, we utilize data of the National Cancer Registry and the Central Statistical Office of Hungary to project future cancer incidence and mortality for major cancer sites for 2020, 2025, and 2030 based on incidence and mortality data collected between 1996 and 2015.

\section{Methods \\ Source of data}

Population-based incidence data for the period between 2001 and 2014 were collected by the National Cancer Registry of Hungary. Mortality data for the time frame between 1996 and 2015 were acquired from the Central Statistical Office of Hungary. The National Cancer Registry of Hungary was established in 2000 to replace former hospital-based data collection systems, and it remains in close contact with community hospitals to ensure the quality of the compiled data. Since 2001, the collected incidence data are publicly available. All cancer cases are classified according to the International Statistical Classification of Diseases and Related Health Problems, 10 th revision. $^{7}$

Demographic projections by age group and sex were based on data obtained from the Hungarian Demographic Research Institute. For mortality calculations and projections, data were tabulated into four 5-year periods (1996-2000, 2001-2005, 2006-2010, and 2011-2015) and three 1-year periods (2020, 2025, and 2030). For calculations and projections of cancer incidence, data were arranged into three 5-year periods (2001-2005, 2006-2010, and 2011-2015) and three 1 -year periods $(2020,2025$, and 2030). The incidence for 2011-2015 was incomplete because of the lag in data availability. The missing values were substituted with the mean of the two most recent years with complete data. In this study, only anonymized patient data were included and analyzed.

\section{Age-standardization of incidence and mortality rates}

Population metrics of the ESP were updated in $2013,{ }^{6}$ based on 2010-2030 population projections. The ESP is the unweighted average of individual populations of EU-27 and European Free Trade Association (EFTA) countries in each 5-year age band. All incidence and mortality data were age standardized to the 2013 ESP and expressed per 100,000 people. $^{6}$

As a consequence of this step, our main results cannot be directly compared with publications using the previous, 1976 ESP data. To overcome this limitation and enable comparison of different metrics, we listed the observed and estimated 
cancer incidence in Hungary by site and sex as (1) crude rates, (2) ASR using the Hungarian population based on the 2011 Hungarian census, (3) ASR using the 1976 ESP, and (4) ASR using the 2013 ESP.

\section{Statistical analysis}

Cancer incidence and mortality were calculated in the $\mathrm{R}$ programming environment using the Nordpred package developed by the Cancer Registry of Norway. ${ }^{8}$ This is a modified age-period-cohort regression model, ${ }^{9}$ with incidence counts assumed to follow a Poisson distribution, based on 5-year age groups and 5-year calendar periods. Birth cohorts were constructed synthetically by subtracting age from period. ${ }^{10}$

The formula of the original age-period-cohort model is: $R_{a p}=\exp \left(A_{a}+D \cdot p+P_{p}+C_{c}\right)$, where $R_{a p}$ is defined as the mortality and incidence rate in age group $(a)$ and in calendar period $(p) ; D$ is the common drift parameter, and the $D$ of the first, second, and third periods was reduced by $0 \%, 25 \%, 50 \%$, respectively; $A_{a}$ is the age component of age group $(a) ; P_{p}$ is defined as the nonlinear period component of period $(p)$; and $C_{c}$ is the nonlinear cohort component of cohort $(c)$. To obtain better predictions, we used the power link function according to the recommendations proposed by Møller et al. ${ }^{7}$ The starting age group of the model was determined by considering the number of deaths or number of cases in each cell. If the number of cases was less than 10 in the age group, future rates were calculated using the average of the last 10 years.

Trends in observed and projected data using segmented line regression were calculated with joinpoint regression, ${ }^{11}$ with up to four joinpoints allowed between 2001-2030 for incidence and 1996-2030 for mortality, following the previously published method. ${ }^{12}$ The likelihood of being diagnosed with cancer and the probability of cancer death were computed with the DevCan software, ${ }^{13}$ according to the previous descriptions of the statistical model. ${ }^{14,15}$

\section{Results Observed cancer cases and deaths, 2006- 2015}

In the past 10 years, a total of 712,785 new cancer cases were diagnosed in Hungary, 364,004 in men and 348,781 in women. This number corresponds to approximately 195 new cancer cases diagnosed per day. In men, LC, CRC, and prostate cancers accounted for $45 \%$ of all cases. Cancers of the oral cavity and pharynx accounted for $8 \%$ of all cases in men. In women, breast, CRC, and LC accounted for $46 \%$ of all cases diagnosed, breast cancer alone responsible for $21 \%$.
In the same time period, 331,119 cancer-related deaths occurred in Hungary, and 33,781 more males died than females. This corresponds to approximately 92 cancer-related deaths per a day. In men, LC and CRC were the most lethal cancers, accounting for $45 \%$ of all cases. Oral cavity and pharynx cancers and prostate cancers each accounted for $7 \%$ of all cancer-related deaths. In females, LC, CRC, and breast cancers were responsible for $20 \%, 14 \%$, and $14 \%$ of all deaths, respectively. The two most lethal cancers, LC and CRC, accounted for $40 \%$ of all cancer-related deaths in the entire population. The observed new cancer cases and deaths in 2006-2015 are summarized in Table 1.

Both the lifetime probability of developing cancer and cancer-related death rate were higher in men $(56.9 \%$ and $27.6 \%$ ) compared to women (51.9\% and $21.7 \%$ ). However, below 50 years of age, cancer risk was higher in females, probably due to the high burden of breast cancer, thyroid cancer, and cancers of the female reproductive organs. Based on the most recent available data, one out of every 10 women was diagnosed with breast cancer, and one in every 10 men with LC.

\section{Demographic shift will boost age groups with high cancer incidence and mortality}

Between 2016 and 2030, the Hungarian population is expected to shrink by $6 \%$ compared to 2015 . The age distribution is forecasted to be heavily skewed (Figure 1) - the number of 60 -year olds and above is estimated to grow roughly by $18 \%$, while $12 \%$ fewer males and $14 \%$ fewer females will be among those aged less than 60 years. The number of those 30-34 years old is expected to be reduced by roughly $24 \%$ in men and $26 \%$ in women.

Cancer primarily affects older individuals. As a consequence, the decreasing proportion of younger generations will result in the marked decline of cohorts with low cancer burden. Accordingly, among the 65-85-year olds, 35\% more patients are projected to be diagnosed with cancer in 2016-2030 compared to 2001-2015 (844,000 vs. 541,000), and $\sim 30 \%$ more cancer-related deaths are expected $(399,000$ vs. 303,000$)$.

The gradually changing population composition will result in discordant trends between crude and ASRs of mortality and the incidence split by sex (Figure 2). In males, the ASR of the overall incidence culminated in 2011-2015, whereas it continues to gently rise in females. The ASR of overall mortality reveals similar directions: a decreasing trend in males and a slow but steady increase in females. 
Table I Distribution of cancer incidence (A) and mortality (B). Incidence and mortality values represent the period 2006-20I5

\begin{tabular}{|c|c|c|c|c|c|c|c|}
\hline \multicolumn{4}{|l|}{ (A) } & \multicolumn{4}{|l|}{ (B) } \\
\hline \multicolumn{4}{|l|}{ Incidence } & \multicolumn{4}{|l|}{ Mortality } \\
\hline \multicolumn{2}{|l|}{ Males } & \multicolumn{2}{|l|}{ Females } & \multicolumn{2}{|l|}{ Males } & \multicolumn{2}{|l|}{ Females } \\
\hline Lung and bronchus & $19.3 \%$ & Breast & $20.9 \%$ & Lung and bronchus & $30.5 \%$ & Lung and bronchus & $19.7 \%$ \\
\hline Colorectal & $15.0 \%$ & Colorectal & $13.2 \%$ & Colorectal & $15.0 \%$ & Colorectal & $14.2 \%$ \\
\hline Prostate & $11.0 \%$ & Lung and bronchus & $12.3 \%$ & Oral cavity and pharynx & $6.8 \%$ & Breast & $14.2 \%$ \\
\hline Oral cavity and pharynx & $7.5 \%$ & Corpus uteri & $4.0 \%$ & Prostate & $6.6 \%$ & Pancreas & $6.5 \%$ \\
\hline Bladder & $5.8 \%$ & Ovary & $3.6 \%$ & Stomach & $5.3 \%$ & Stomach & $4.9 \%$ \\
\hline Stomach & $3.8 \%$ & Pancreas & $3.6 \%$ & Pancreas & $5.0 \%$ & Ovary & $4.7 \%$ \\
\hline Kidney & $3.4 \%$ & Melanoma of skin & $3.2 \%$ & Bladder & $3.4 \%$ & Leukemia & $3.0 \%$ \\
\hline Pancreas & $3.3 \%$ & Cervix uteri & $3.1 \%$ & Liver & $2.8 \%$ & Gallbladder and biliary tract & $2.9 \%$ \\
\hline Larynx & $2.8 \%$ & Stomach & $3.0 \%$ & Esophagus & $2.7 \%$ & Cervix uteri & $2.8 \%$ \\
\hline Melanoma of skin & $2.7 \%$ & Bladder & $2.7 \%$ & Larynx & $2.6 \%$ & Brain & $2.0 \%$ \\
\hline Brain & $2.6 \%$ & Oral cavity and pharynx & $2.7 \%$ & Leukemia & $2.6 \%$ & Oral cavity and pharynx & $1.9 \%$ \\
\hline Leukemia & $2.5 \%$ & Kidney & $2.6 \%$ & Kidney & $2.4 \%$ & Kidney & $1.9 \%$ \\
\hline Liver & $2.5 \%$ & Non-Hodgkin lymphoma & $2.5 \%$ & Brain & $1.7 \%$ & Non-Hodgkin lymphoma & $1.9 \%$ \\
\hline Non-Hodgkin lymphoma & $2.2 \%$ & Brain & $2.5 \%$ & Non-Hodgkin lymphoma & $1.6 \%$ & Liver & $1.8 \%$ \\
\hline Esophagus & $1.9 \%$ & Leukemia & $2.4 \%$ & Gallbladder and biliary tract & $1.2 \%$ & Bladder & $1.8 \%$ \\
\hline Soft tissue & $1.8 \%$ & Soft tissue & $2.0 \%$ & Melanoma of skin & $1.1 \%$ & Corpus uteri & $1.8 \%$ \\
\hline Testis & $1.6 \%$ & Gallbladder and biliary tract & $1.9 \%$ & Multiple myeloma & $0.7 \%$ & Melanoma of skin & $1.0 \%$ \\
\hline Gallbladder and biliary tract & $1.2 \%$ & Liver & $1.8 \%$ & Testis & $0.3 \%$ & Multiple myeloma & $1.0 \%$ \\
\hline Bones and joints & $1.0 \%$ & Thyroid & $1.4 \%$ & Bones and joints & $0.1 \%$ & Esophagus & $0.7 \%$ \\
\hline Thyroid & $0.4 \%$ & Bones and joints & $0.9 \%$ & Hodgkin lymphoma & $0.1 \%$ & Larynx & $0.4 \%$ \\
\hline Other & $7.6 \%$ & Other & $9.5 \%$ & Other & $7.6 \%$ & Bones and joints & $0.1 \%$ \\
\hline \multirow[t]{3}{*}{ All sites } & $100 \%$ & All sites & $100 \%$ & All sites & $100 \%$ & Hodgkin lymphoma & $0.1 \%$ \\
\hline & & & & & & Other & $10.8 \%$ \\
\hline & & & & & & All sites & $100 \%$ \\
\hline
\end{tabular}

\section{The mean annual percentage increase in incidence is over $1.35 \%$}

The mean annual percentage change (APC) in crude rates of cancer incidence modeled by joinpoint regression predicts a $1.35 \%$ annual increase between 2001 and 2030 in male overall incidence and a 1.68\% annual increase between 2013 and 2030 in female overall incidence $(p<0.05)$ (Figure 2). In males, the LC incidence rates are in a steady decline (Figure 3), yet the steep increase in the incidence of other major cancer types (e.g., prostate, bladder, kidney, pancreas, CRC) explains the overall increase in incidence for 2001-2014, with similar tendencies expected in the future (Table 2A). A numerical example of the age-period-cohort model in males illustrates the performed calculations in Supplementary materials. In females, accelerated annual growth characterizes many of the less frequent cancer types, such as thyroid, liver, bladder, and kidney cancers and non-Hodgkin lymphoma, with rates projected to persist for 2015-2030 (Table 2A).

The annual percent change in crude overall mortality based on joinpoint regression analysis from 1996 through 2030 projects a $0.78 \%$ annual increase in the overall mortality rate in males between 2015 and 2030 and a $1.47 \%$ annual increase between 2008 and 2030 for females $(p<0.05)$ (Figure 2). The inflated female trends are partly caused by the steep increase in LC-related mortality. In addition, the annual increase will be higher in several (e.g., pancreas, kidney) cancer-related mortalities for females compared to males (Table 2B).

\section{Current and projected cancer incidence and mortality trends by site of origin}

In males, the incidence of CRC, with its calculated $2.1 \%$ annual increase, is projected to surpass $\mathrm{LC}$ and is predicted to be the most common cancer by 2020 (Table 3). The incidence of prostate cancer, with an astounding 3.6\% annual increase, is expected to achieve the top position alongside CRC (Table 3) in males 60 years and up (Table 4A). The incidence of prostate cancer is age dependent, but it is predicted to be among the five most common cancers in men as young as 40 . Oral cavity/pharynx cancer along with kidney cancer will be frequent among 40-59-year-old males, as will bladder cancer among those over 60 years of age (Table 4A). The annual increases in pancreas, bladder, stomach, and kidney 

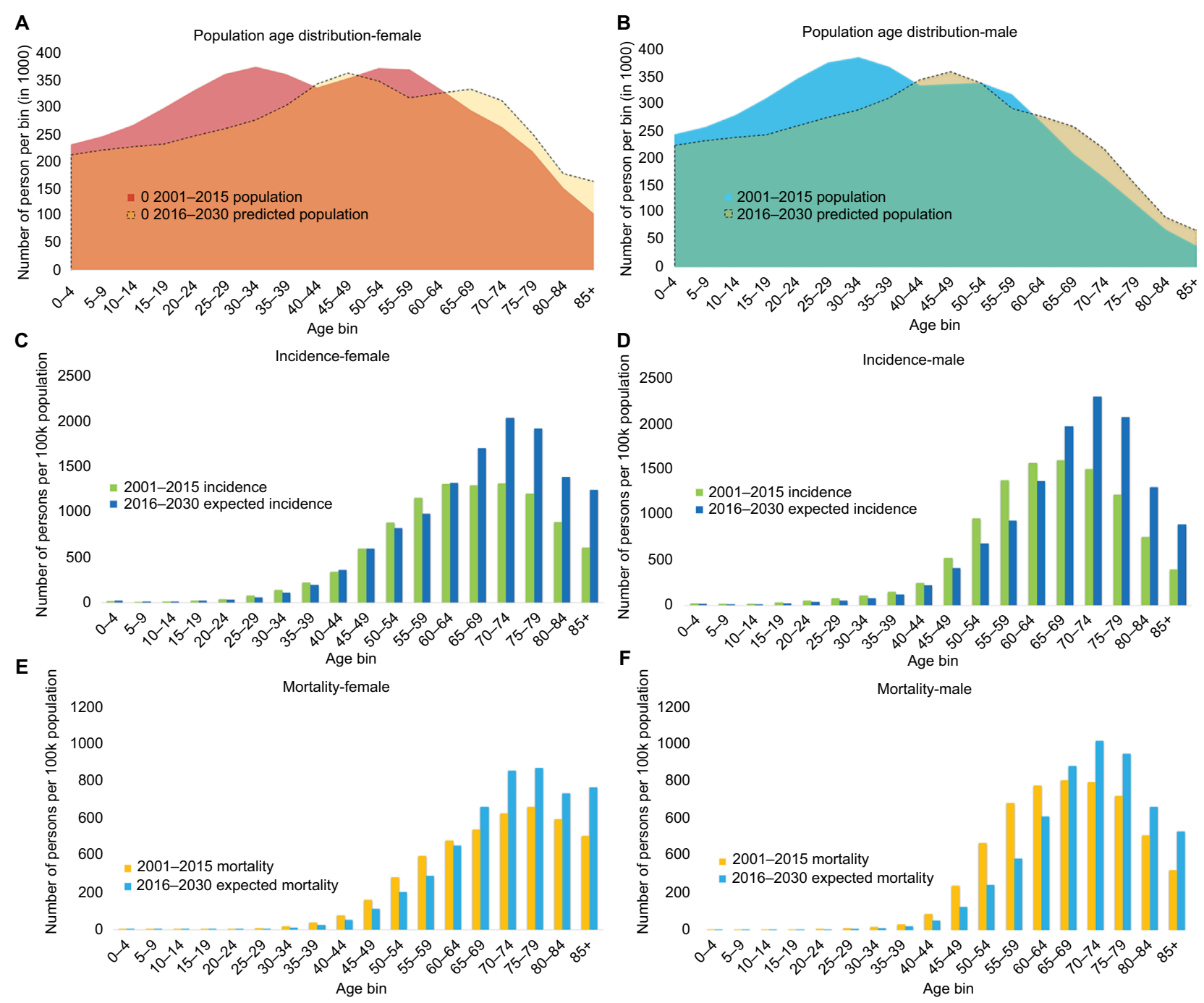

Figure I Upcoming shift in population age distribution increases the number of new cancer cases.

Note: Population age distribution in female (A) and male (B), cancer incidence rates in female (C) and male (D), and mortality in women (E) and men (F).

cancer-related mortality are projected to continue in the future (Table 2B), and by 2030, besides LC and CRC, prostate, pancreas, bladder, and stomach cancers are predicted to be the most common causes of cancer-related deaths among men (Table 3).

Among those aged 20-39 years, the incidences of testicular cancer and melanoma are forecasted to precede CRC. Non-Hodgkin lymphoma and brain cancers will also be on the rise (Table 4A). Among the less common tumor types, the incidence of thyroid cancer ( $3.2 \%$ annually) is estimated to grow with the fastest pace (Table 2A).

LC-related mortality has already climaxed in males (Figure 3), yet it remains a top killer among those aged 40-79 years (Table 4B). Oral cavity and pharynx cancerrelated mortality started a steep, uninterrupted decline in 2006-2015 (Table 2B), while it remains among the three most common death-causing cancers among those aged 40-59 years (Table 4B).

In females, the incidences of breast cancer, CRC, and LC are projected to remain in the top positions until 2030 (Table 3). However, among those 20-39 years old, the incidences of melanoma, cervix uteri, and thyroid cancers are projected to surpass CRC and LC (Table 4A). The incidence of breast cancer is predicted to rise predominantly among those 40-59 years old. Pancreas cancer, with its estimated $3 \%$ annual increase, is estimated to reach $4 \%$ incidence by 2020, mainly affecting women past 60 years of age (Table 4A). Among less common cancer types, the increases in the incidences of thyroid, soft tissue, and liver cancers will be considerable (Table 2A). LC, CRC, breast cancer, and pancreas cancer are predicted to remain top causes of cancer-related death in females through 2030 (Table 3). The 

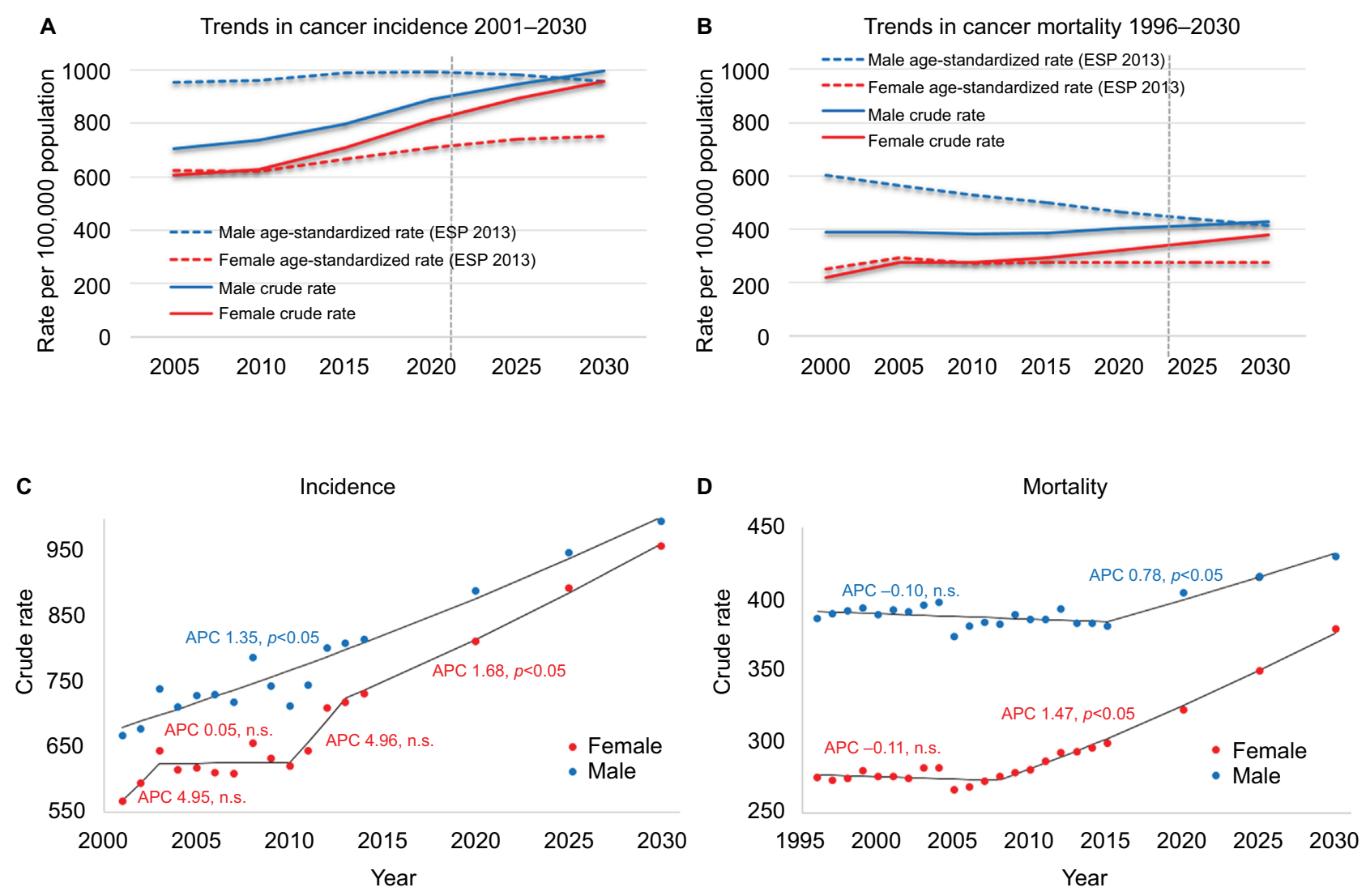

Figure 2 Standardized cancer rates remain steady while a positive gain in annual percent change (APC) leads to increasing crude rates.

Notes: Trends in cancer incidence $(\mathbf{A})$ and mortality $(\mathbf{B})$. Male and female Hungarian crude rates of incidence and mortality are compared to age-standardized rates based on the 2013 European Standard population (ESP 20I3). Solid lines represent actual data while dashed lines express data estimated by the age-period-cohort model. Every $x$-value represents a 5-year bin. Mean annual percent change in crude rates of male and female incidence (C) and mortality (D) modeled by joinpoint regression analysis. Positive APC values represent increase, negative values decrease in mortality rates.

Abbreviation: n.s., not significant.

steep increase in mortality already present in 1996-2005 is expected to continue for bladder, pancreas, and ovarian cancers. Ovarian cancer will be among the top five deathcausing cancers among women aged 40-79 years, surpassed by stomach cancer-related mortality among those aged $80+$ years (Table 4B). Mortality and incidence trends are depicted as both crude rates and ASRs for each major cancer type in Figure 4A for women and Figure 4B for men.

\section{Comparing different reference populations}

To study cancer rates standardized to different reference populations, we compared cancer incidence and mortality by site (standardized to the $1976 \mathrm{ESP}$ ) with the 2012 estimates of overall European cancer incidence and mortality. ${ }^{3} \mathrm{Of}$ the most rampant cancers, a $45 \%$ higher incidence rate of $\mathrm{LC}$ among males and $56 \%$ among females was observed in Hungary. For pancreas cancer, the incidence was $46 \%$ and $41 \%$ higher in males and females, respectively, and for CRC the incidence was $41 \%$ higher among men and $36 \%$ among women. The incidence of gallbladder cancer among men and women was $65 \%$ and $58 \%$ higher, respectively. The incidence of cancers of the oral cavity and pharynx was $63 \%$ and $61 \%$ higher among males and females, respectively, than the estimated European average. Mortality from oral cavity/pharynx cancer and larynx cancer was $67 \%$ and $59 \%$ higher, respectively, than the European average among men. CRC-related death was $52 \%$ greater in men and $41 \%$ greater in women than the European average, and $42 \%$ versus $49.5 \%$ greater mortality was observed among males and females, respectively, as a result of LC. We list the observed and estimated cancer incidences in Hungary by site and sex in Table S1 as (1) crude rates, (2) ASRs using the Hungarian population based on the 2011 Hungarian census, (3) ASRs using the 1976 ESP, and (4) ASRs using the 2013 ESP. Mortality data with the same standardization parameters are listed in Table S2. 
A

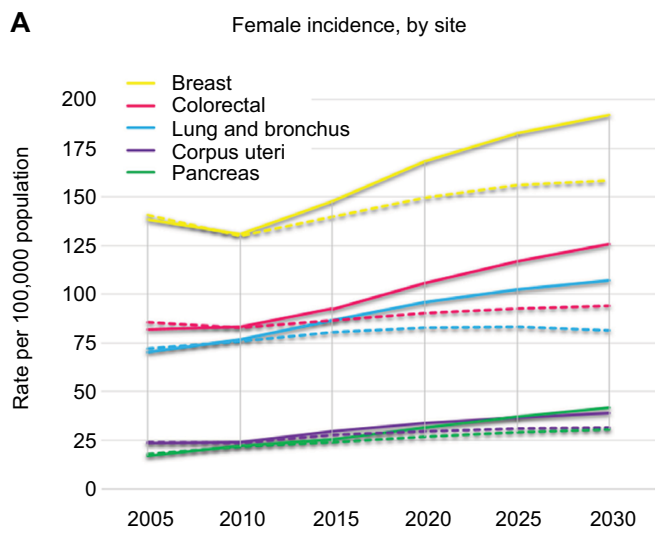

C

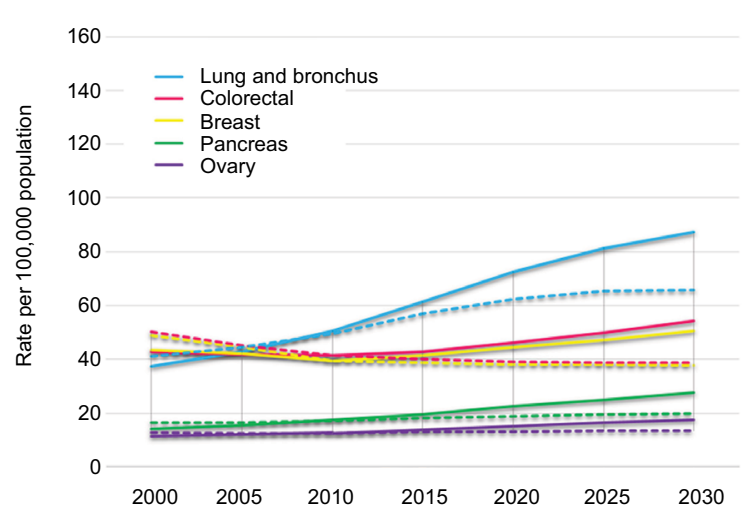

B

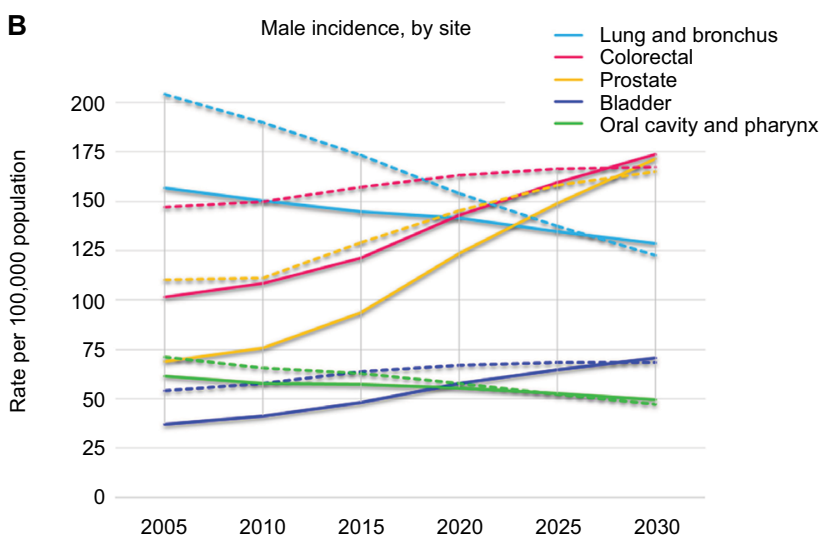

D

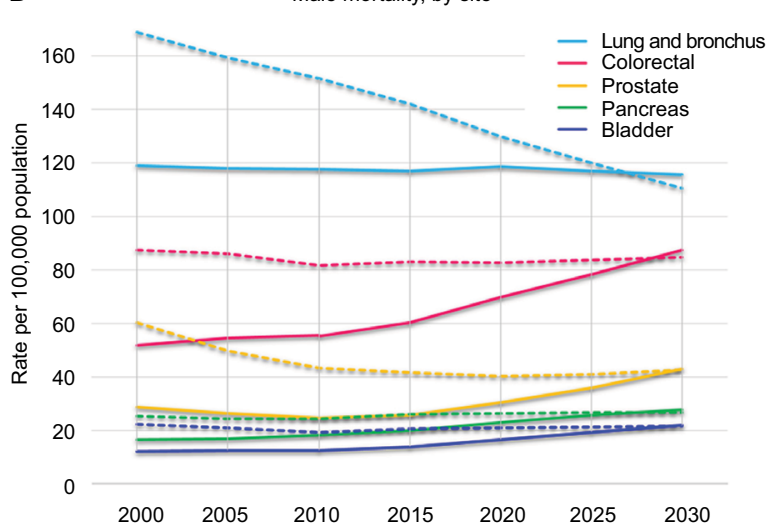

Figure 3 Trends in incidence ( $\mathbf{A}$ and $\mathbf{B})$ and mortality $(\mathbf{C}$ and $\mathbf{D})$ in the five most common cancers by sex.

Notes: Solid lines represent crude rates, dashed lines represent rates age-adjusted to the 2013 ESP. For 2020, 2025, 2030 data are estimated by the age-period-cohort model. Abbreviation: ESP, European Standard population.

Table 2 Mean annual percent change (APC) and $95 \% \mathrm{Cl}$ by sex in crude rate of incidence (A) and mortality (B) by site and time

(A)

APC, incidence in men (lower $\mathrm{Cl}$-upper $\mathrm{Cl}$ )

\begin{tabular}{|c|c|c|}
\hline Site & $2001-2014$ & $2015-2030$ \\
\hline Lung and bronchus & $-0.7^{*}(-0.9$ to -0.5$)$ & $-0.7^{*}(-0.9$ to -0.5$)$ \\
\hline Colorectal & $2.1 *(1.9$ to 2.3$)$ & $2.1 *(1.9$ to 2.3$)$ \\
\hline Prostate & $3.6 *(3.1$ to 4.1$)$ & $3.6 *(3.1$ to 4.1$)$ \\
\hline Oral cavity and pharynx & $-0.7^{*}(-1.0$ to -0.4$)$ & $-0.7^{*}(-1.0$ to -0.4$)$ \\
\hline Bladder & $2.5^{*}(2.2$ to 2.9$)$ & $2.5^{*}(2.2$ to 2.9$)$ \\
\hline Stomach & $-0.2(-0.6$ to 0.1$)$ & $-0.2(-0.6$ to 0.1$)$ \\
\hline Kidney & $2.4^{*}(2.0$ to 2.7$)$ & $2.4 *(2.0$ to 2.7$)$ \\
\hline Pancreas & $2.6 *(2.2$ to 2.9$)$ & $2.6^{*}(2.2$ to 2.9$)$ \\
\hline Larynx & $-1.2 *(-1.7$ to -0.8$)$ & $-1.2^{*}(-1.7$ to -0.8$)$ \\
\hline Brain & $0.8 *(0.5$ to 1.1$)$ & $0.8^{*}(0.5$ to 1.1$)$ \\
\hline Leukemia & $2.3 *(1.9$ to 2.7$)$ & $2.3 *(1.9$ to 2.7$)$ \\
\hline Melanoma of skin & $6.0 *(4.2$ to 7.9$)$ & $3.1^{*}(2.3$ to 3.9$)$ \\
\hline Liver & $4.1 *(2.7$ to 5.4$)$ & $1.9 *(1.3$ to 2.6$)$ \\
\hline Non-Hodgkin lymphoma & $2.6 *(2.2$ to 3.0$)$ & $2.6 *(2.2$ to 3.0$)$ \\
\hline Esophagus & $-0.8^{*}(-1.2$ to -0.4$)$ & $-0.8^{*}(-1.2$ to -0.4$)$ \\
\hline Testis & $2.0 *(1.1$ to 2.8$)$ & $0.3(-0.3$ to -0.9$)$ \\
\hline Gallbladder and biliary tract & $2.4^{*}(1.9$ to 3.0$)$ & $2.4 *(1.9$ to 3.0$)$ \\
\hline Soft tissue & $5.9 *(3.3$ to 8.6$)$ & $2.3 *(1.2$ to 3.5$)$ \\
\hline Bones and joints & $0.1(-0.6$ to 0.7$)$ & $0.1(-0.6$ to 0.7$)$ \\
\hline Thyroid & $3.2^{*}(2.7$ to 3.7$)$ & $3.2 *(2.7$ to 3.7$)$ \\
\hline
\end{tabular}

APC, incidence in women (lower $\mathrm{Cl}$-upper $\mathrm{Cl}$ )

\begin{tabular}{|c|c|c|}
\hline Site & $200 I-2014$ & $2015-2030$ \\
\hline Breast & I.5 (-0.6 to 3.7$)$ & $1.9 *(1.6$ to 2.2$)$ \\
\hline Colorectal & $1.3 *(1.1$ to 1.5$)$ & $1.3^{*}(1.1$ to 1.5$)$ \\
\hline Lung and bronchus & $1.7 *(1.4$ to 1.9$)$ & $1.7^{*}(1.4$ to 1.9$)$ \\
\hline Corpus uteri & $2.1 *(1.7$ to 2.4$)$ & $2.1 *(1.7$ to 2.4$)$ \\
\hline Cervix uteri & $-0.8(-2.8$ to 1.2$)$ & $0.5(-0.9$ to 1.9$)$ \\
\hline Ovary & $1.4(-0.3$ to 3.2$)$ & $0.8^{*}(0.3$ to 1.3$)$ \\
\hline Stomach & $0.1(-0.2$ to 0.4$)$ & $0.1(-0.2$ to 0.4$)$ \\
\hline Pancreas & $4.3 *(3.2$ to 5.4$)$ & $3.0^{*}(2.5$ to 3.4$)$ \\
\hline Oral cavity and pharynx & $2.7^{*}(0.1$ to 5.4$)$ & $1.5^{*}(0.9$ to 2.1$)$ \\
\hline Brain & $0.7^{*}(0.3$ to $\mathrm{I} .2)$ & $0.7^{*}(0.3$ to 1.2$)$ \\
\hline Melanoma of skin & $4.6 *(1.5$ to 7.9$)$ & $2.6^{*}(2.2$ to 2.3$)$ \\
\hline Bladder & $2.9 *(2.5$ to 3.3$)$ & $2.9^{*}(2.5$ to 3.3$)$ \\
\hline Leukemia & $1.6 *(1.2$ to 2.0$)$ & $1.6^{*}(1.2$ to 2.0$)$ \\
\hline Kidney & $2.3 *(2.0$ to 2.6$)$ & $2.3^{*}(2.0$ to 2.6$)$ \\
\hline Gallbladder and biliary tract & $0.7 *(0.7$ to 1.2$)$ & $0.7^{*}(0.7$ to 1.2$)$ \\
\hline Non-Hodgkin lymphoma & $4.2 *(3.3$ to 5.0$)$ & $2.6 *(1.3$ to 3.8$)$ \\
\hline Liver & $2.1 *(1.6$ to 2.6$)$ & $2.1 *(1.6$ to 2.6$)$ \\
\hline Soft tissue & $5.6 *(2.7$ to 8.7$)$ & $1.7^{*}(0.6$ to 2.8$)$ \\
\hline Thyroid & $4.2 *(1.2$ to 7.3$)$ & $2.5^{*}(1.8$ to 3.3$)$ \\
\hline Bones and joints & $0.1(-0.5$ to 0.7$)$ & $0.1(-0.5$ to 0.7$)$ \\
\hline
\end{tabular}

(Continued) 


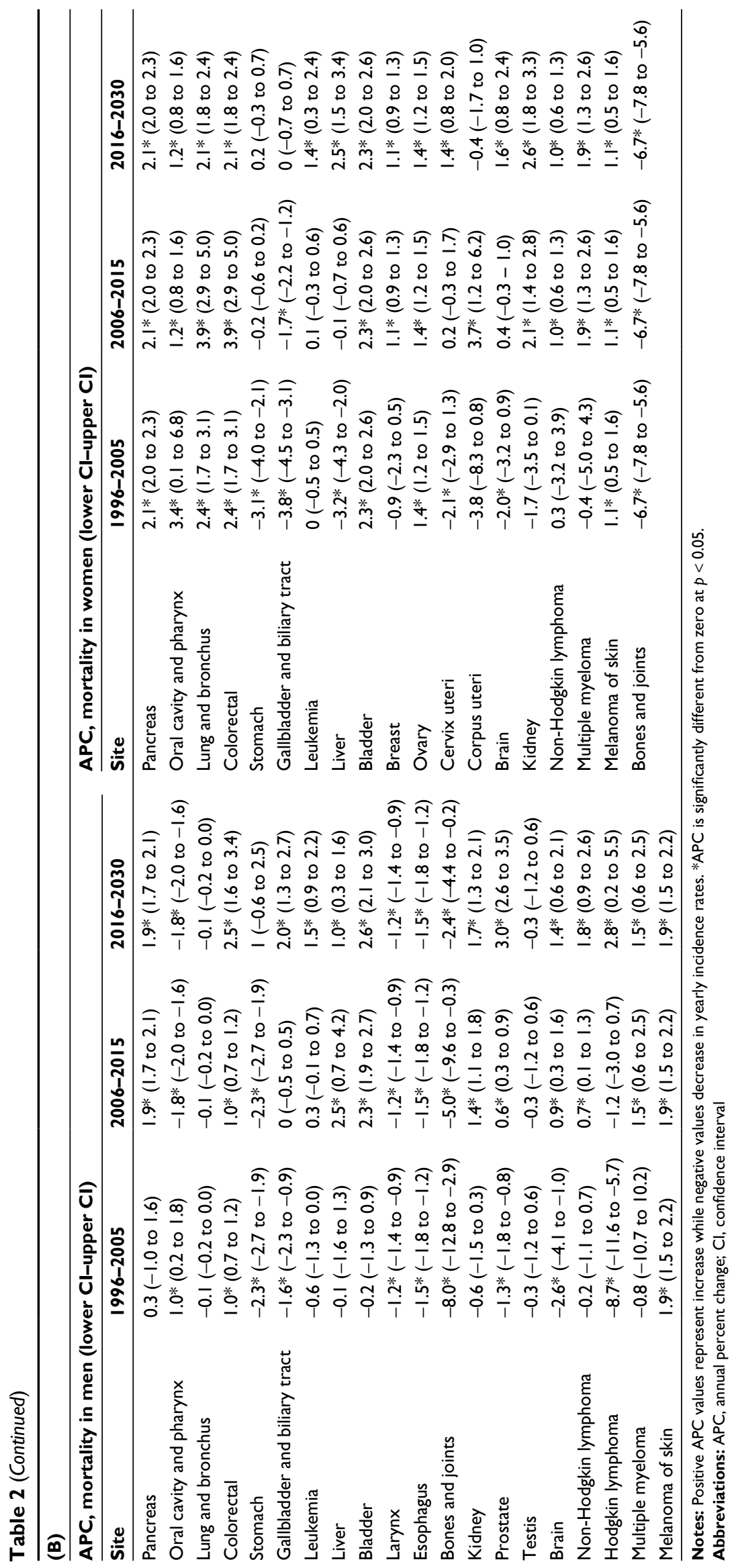


Table 3 Ranking of incidence (A) and mortality (B) by expected percentages of the top 10 tumor types in males and females in 2020, 2025 , and 2030

\begin{tabular}{|c|c|c|c|c|c|c|c|c|c|}
\hline \multicolumn{5}{|l|}{ (A) } & \multicolumn{5}{|l|}{ (B) } \\
\hline \multicolumn{5}{|c|}{ Incidence } & \multicolumn{5}{|c|}{ Mortality } \\
\hline & Males & & Females & & & Males & & Females & \\
\hline \multirow[t]{11}{*}{2020} & Colorectal & $16 \%$ & Breast & $19 \%$ & 2020 & Lung and bronchus & $29 \%$ & Lung and bronchus & $22 \%$ \\
\hline & Lung and bronchus & $16 \%$ & Colorectal & $12 \%$ & & Colorectal & $17 \%$ & Colorectal & $14 \%$ \\
\hline & Prostate & $14 \%$ & Lung and bronchus & $11 \%$ & & Prostate & $8 \%$ & Breast & $14 \%$ \\
\hline & Bladder & $7 \%$ & Corpus uteri & $4 \%$ & & Pancreas & $6 \%$ & Pancreas & $7 \%$ \\
\hline & Oral cavity and pharynx & $6 \%$ & Pancreas & $4 \%$ & & Oral cavity and pharynx & $6 \%$ & Ovary & $5 \%$ \\
\hline & Kidney & $4 \%$ & Ovary & $3 \%$ & & Stomach & $5 \%$ & Stomach & $4 \%$ \\
\hline & Pancreas & $4 \%$ & Melanoma of skin & $3 \%$ & & Bladder & $4 \%$ & Leukemia & $3 \%$ \\
\hline & Melanoma of skin & $3 \%$ & Bladder & $3 \%$ & & Liver & $3 \%$ & Cervix uteri & $3 \%$ \\
\hline & Stomach & $3 \%$ & Cervix uteri & $3 \%$ & & Leukemia & $3 \%$ & Gallbladder and biliary tract & $2 \%$ \\
\hline & Leukemia & $3 \%$ & Non-Hodgkin lymphoma & $3 \%$ & & Kidney & $3 \%$ & Kidney & $2 \%$ \\
\hline & Other & $24 \%$ & Other & $35 \%$ & & Other & $17 \%$ & Other & $24 \%$ \\
\hline \multirow[t]{11}{*}{2025} & Colorectal & $17 \%$ & Breast & $20 \%$ & 2025 & Lung and bronchus & $28 \%$ & Lung and bronchus & $23 \%$ \\
\hline & Prostate & $16 \%$ & Colorectal & $12 \%$ & & Colorectal & $19 \%$ & Colorectal & $14 \%$ \\
\hline & Lung and bronchus & $14 \%$ & Lung and bronchus & $11 \%$ & & Prostate & $9 \%$ & Breast & $14 \%$ \\
\hline & Bladder & $7 \%$ & Pancreas & $4 \%$ & & Pancreas & $6 \%$ & Pancreas & $7 \%$ \\
\hline & Oral cavity and pharynx & $6 \%$ & Corpus uteri & $4 \%$ & & Stomach & $5 \%$ & Ovary & $5 \%$ \\
\hline & Kidney & $4 \%$ & Melanoma of skin & $3 \%$ & & Oral cavity and pharynx & $5 \%$ & Stomach & $4 \%$ \\
\hline & Pancreas & $4 \%$ & Ovary & $3 \%$ & & Bladder & $5 \%$ & Leukemia & $3 \%$ \\
\hline & Melanoma of skin & $4 \%$ & Bladder & $3 \%$ & & Liver & $3 \%$ & Cervix uteri & $3 \%$ \\
\hline & Stomach & $3 \%$ & Non-Hodgkin lymphoma & $3 \%$ & & Leukemia & $3 \%$ & Kidney & $2 \%$ \\
\hline & Leukemia & $3 \%$ & Kidney & $3 \%$ & & Kidney & $3 \%$ & Gallbladder and biliary tract & $2 \%$ \\
\hline & Other & $23 \%$ & Other & $34 \%$ & & Other & $15 \%$ & Other & $23 \%$ \\
\hline \multirow[t]{11}{*}{2030} & Colorectal & $18 \%$ & Breast & $20 \%$ & 2030 & Lung and bronchus & $27 \%$ & Lung and bronchus & $23 \%$ \\
\hline & Prostate & $17 \%$ & Colorectal & $12 \%$ & & Colorectal & $21 \%$ & Colorectal & $14 \%$ \\
\hline & Lung and bronchus & $13 \%$ & Lung and bronchus & $11 \%$ & & Prostate & $10 \%$ & Breast & $13 \%$ \\
\hline & Bladder & $7 \%$ & Pancreas & $4 \%$ & & Pancreas & $7 \%$ & Pancreas & $7 \%$ \\
\hline & Oral cavity and pharynx & $5 \%$ & Corpus uteri & $4 \%$ & & Bladder & $5 \%$ & Ovary & $5 \%$ \\
\hline & Kidney & $4 \%$ & Melanoma of skin & $3 \%$ & & Stomach & $5 \%$ & Stomach & $4 \%$ \\
\hline & Melanoma of skin & $4 \%$ & Ovary & $3 \%$ & & Oral cavity and pharynx & $4 \%$ & Leukemia & $3 \%$ \\
\hline & Pancreas & $4 \%$ & Bladder & $3 \%$ & & Liver & $4 \%$ & Cervix uteri & $3 \%$ \\
\hline & Leukemia & $3 \%$ & Non-Hodgkin lymphoma & $3 \%$ & & Leukemia & $3 \%$ & Kidney & $2 \%$ \\
\hline & Stomach & $3 \%$ & Soft tissue & $3 \%$ & & Kidney & $3 \%$ & Bladder & $2 \%$ \\
\hline & Other & $22 \%$ & Other & $34 \%$ & & Other & $12 \%$ & Other & $24 \%$ \\
\hline
\end{tabular}

Note: Incidence and mortality are expressed as mean values for each year.

When comparing cancer incidence to the 2010-2012 US data, ${ }^{16}$ the likelihood of developing LC and CRC was strikingly higher in both males and females, as was the probability of cancer risk over all sites, compared to the US (Table S3). The observed incidence rates of CRC, LC, oral cavity and pharynx cancer, bladder cancer, larynx cancer, melanoma, brain cancer, and testicular cancer were higher in Hungarian men compared to the 2012 estimated values of the worldwide male population, and the CRC, LC, pancreas cancer, melanoma, brain cancer, and kidney cancer incidence rates were greater among Hungarian women than the predicted rates of the worldwide female population. Similar trends persist when comparing cancerrelated mortality: the percentage of men who died from
LC, CRC, oral cavity and pharynx cancer, pancreas cancer, and larynx cancer and the percentage of women who died from LC, CRC, and pancreas cancer were higher than the worldwide averages.

\section{Discussion}

Current scientific literature uses the yearly published prospective cancer incidence and mortality statistics of the USA as the gold standard for cancer epidemiology; ${ }^{16}$ the 2015 version of this report was already cited over 25,000 times. However, the age and demographic distribution of the US population is fundamentally different from other developed countries in Europe and Asia. These issues make the US data unreliable when projected to these countries. 


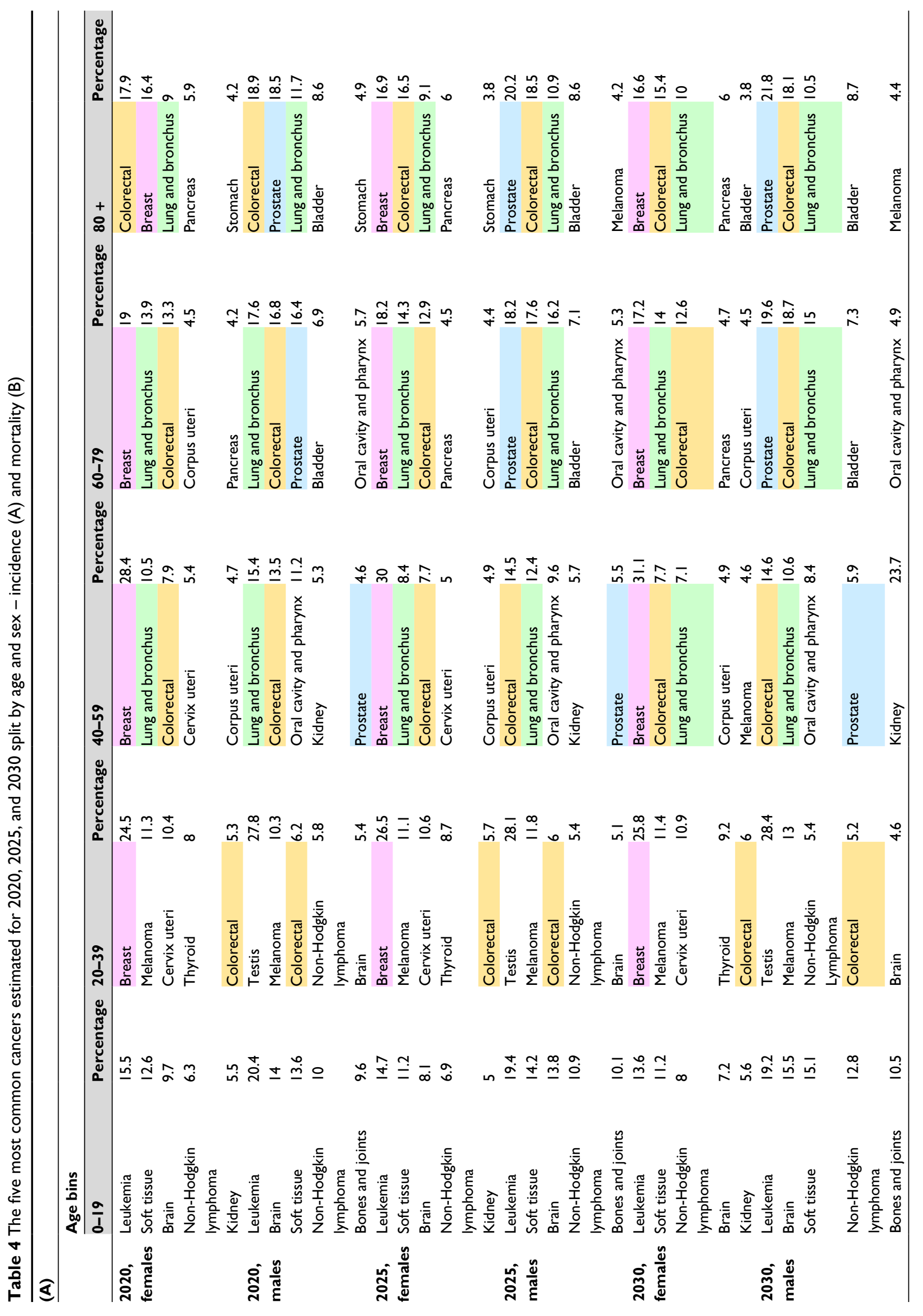




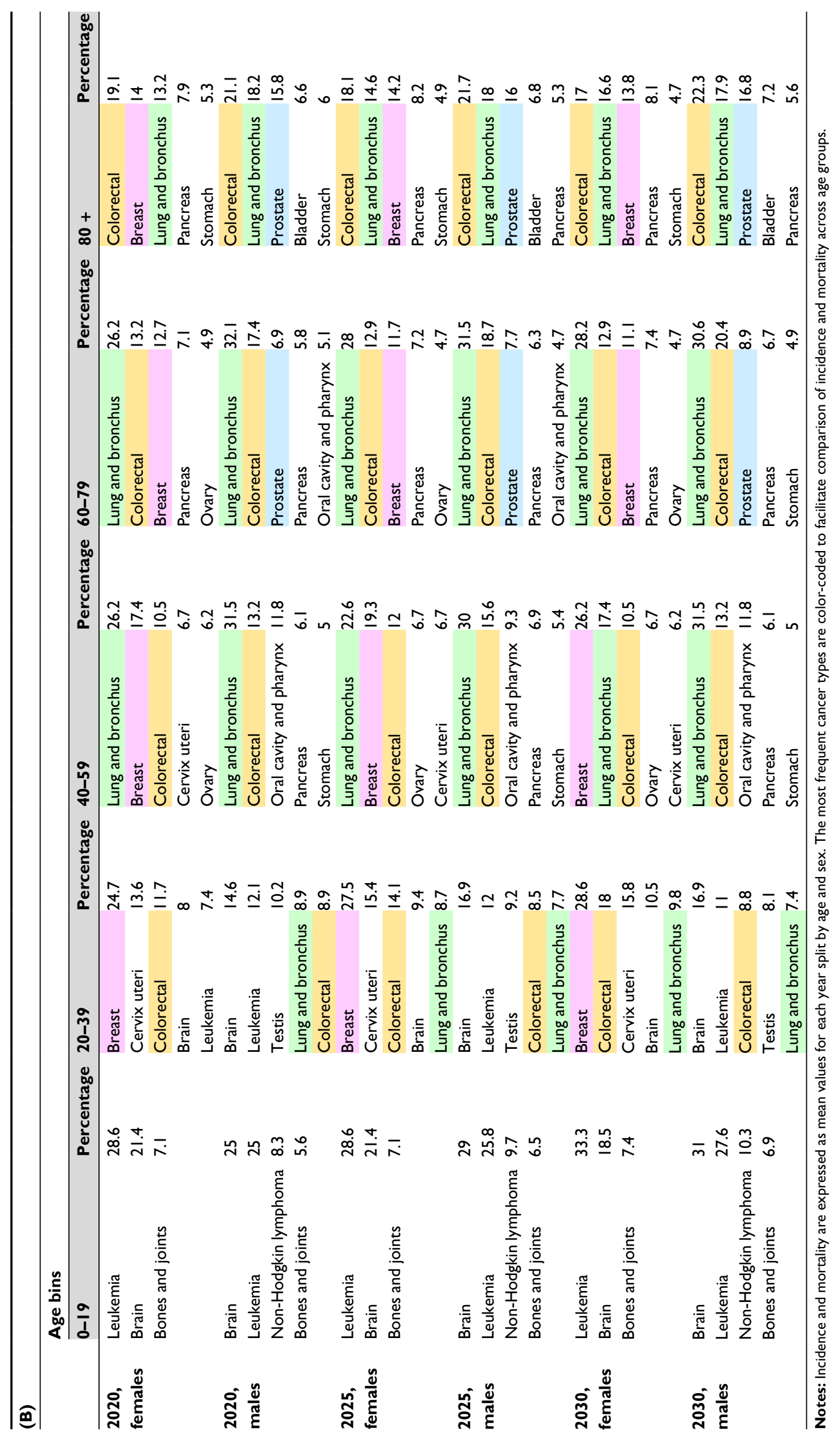


Another concern of statistical analyses is the ESP, for which the first update since 1976 was in 2013. This means that rates standardized to the previous ESP are hardly comparable with recent data due to the rapid demographic shifts. Central and Eastern European countries share a similar history, have undergone comparable shifts in demography, and are facing similar challenges in their cancer epidemics. Within this region, with its $100 \%$ population coverage and relatively high autopsy rates, Hungarian statistics provide reliable data regarding trends in cancer epidemiology and the expected cancer rates for the near future, with the possibility of extrapolating projections for countries with similar trends in demography and cancer
A
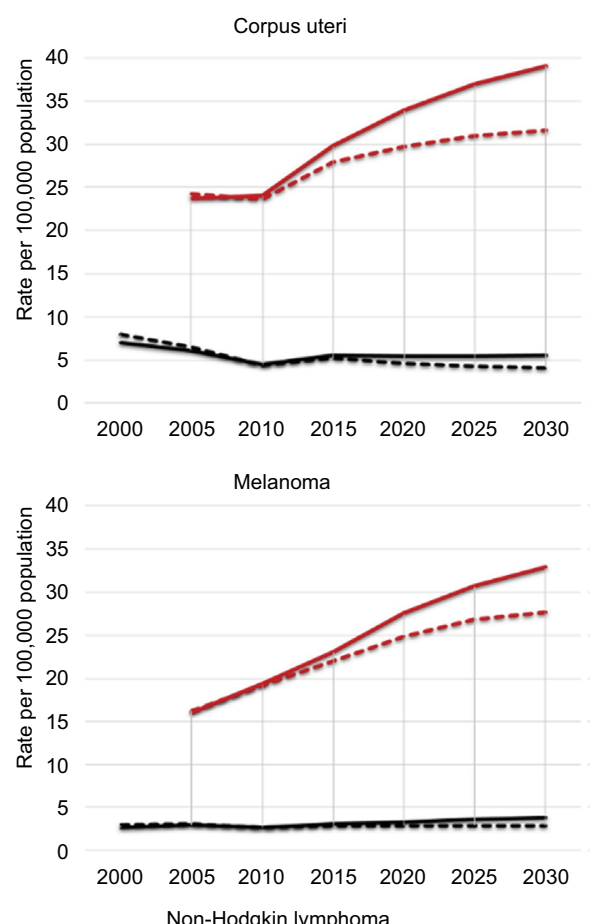

일

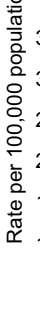

0

2000

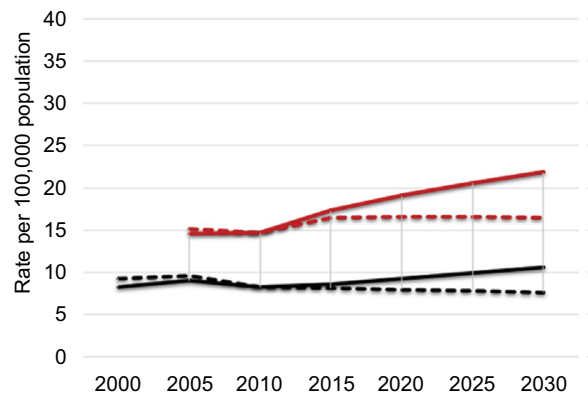

Figure 4 (Continued)
Females
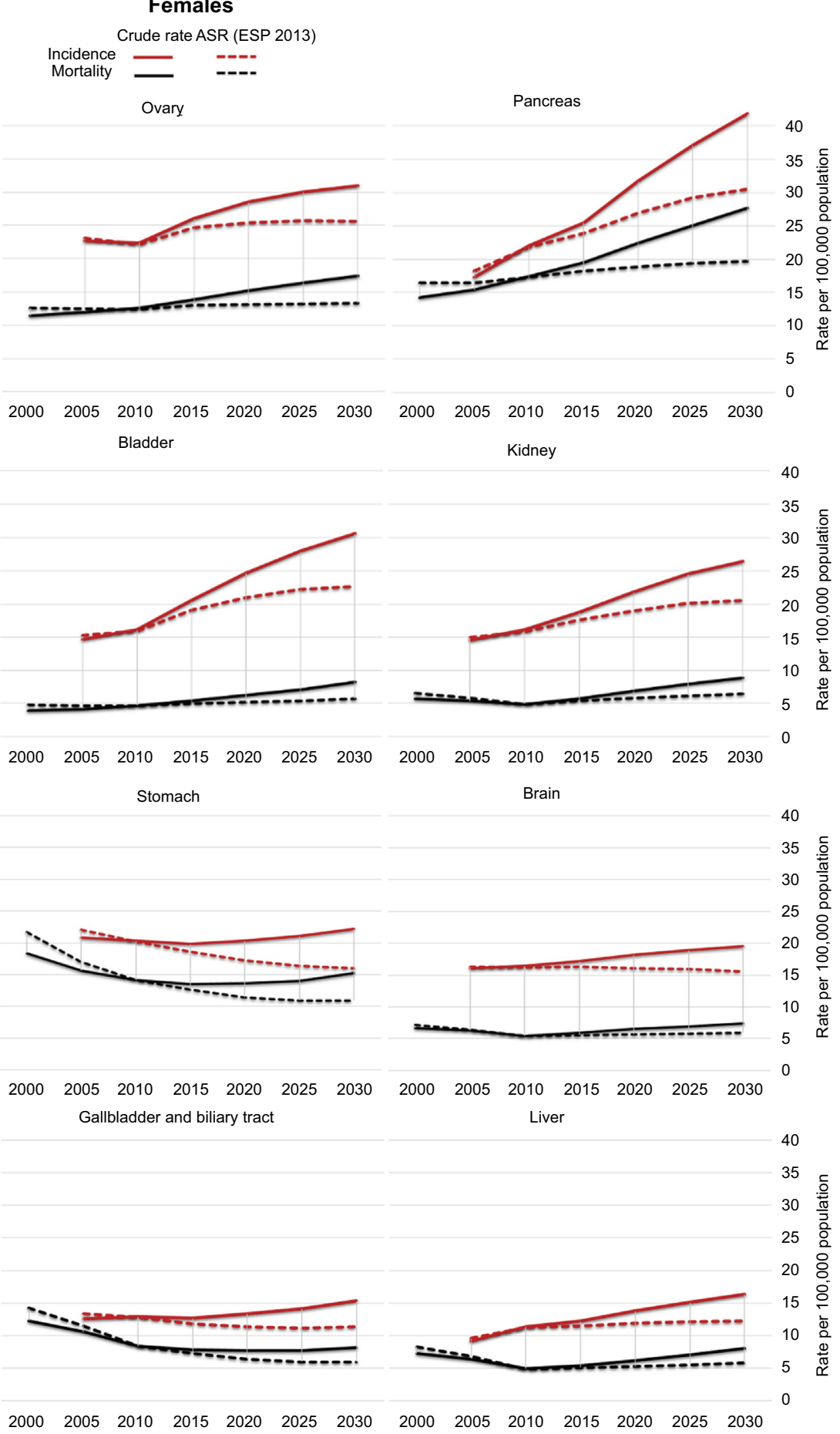
B

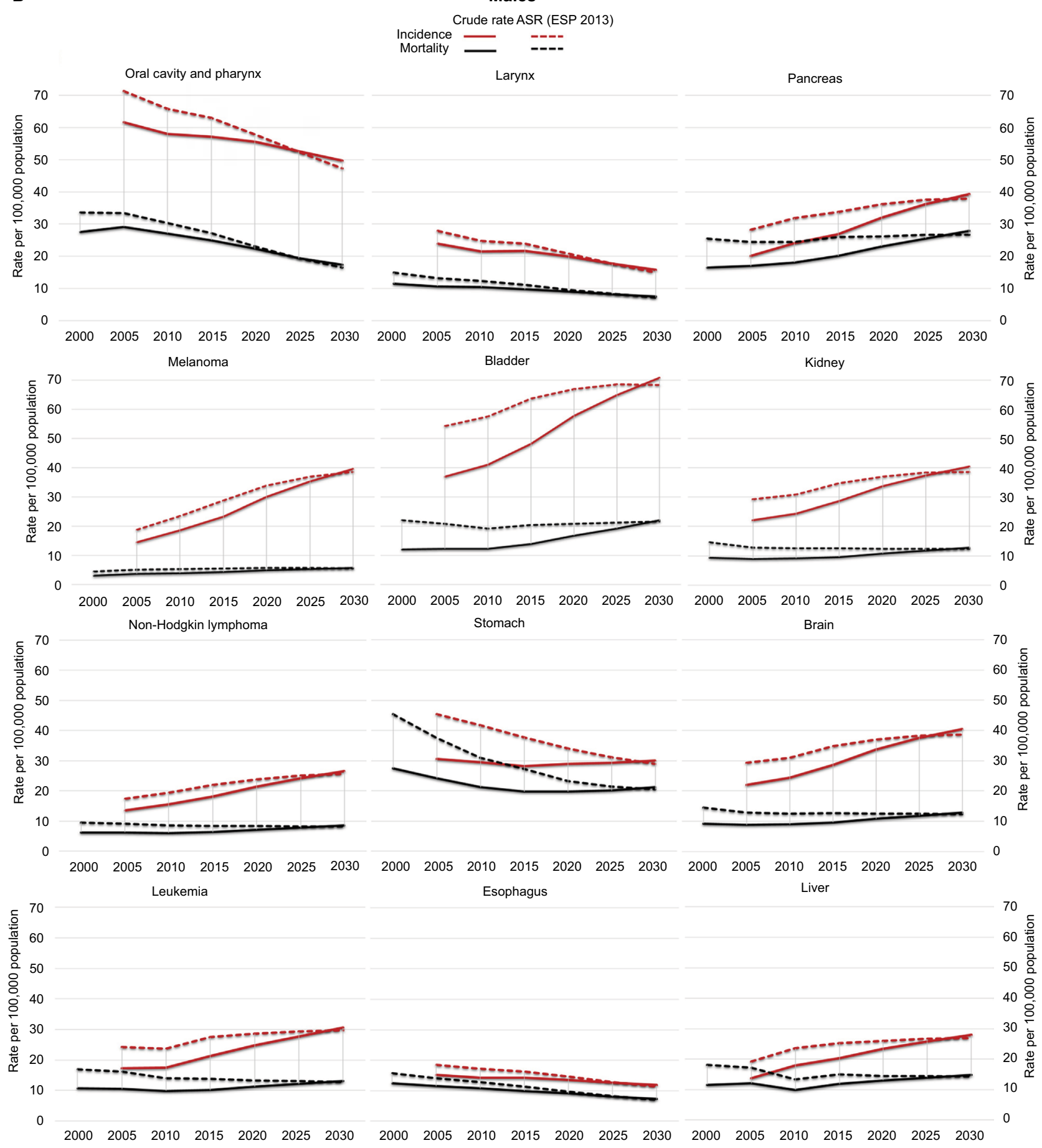

Figure 4 Observed and projected tendencies of incidence and mortality in selected cancers in females (A) and males (B).

Note: Solid lines are crude rates, dashed lines represent rates age-adjusted to the 2013 ESP (ASR ESP 20I3).

Abbreviations: ASR, age-standardized rate; ESP, European Standard Population.

rates. However, our results cannot be generalized, although, in other countries of the European Union (e.g., France, Belgium, and Denmark), the overall cancer incidence estimates for 2012 surpassed those of Hungary, the expected mortality was predicted in some cases to be as much as $30 \%$ lower. $^{3}$ The discrepancy between per capita health expenditures between different countries may partially explain the disparity in expected mortality. ${ }^{17}$ The escalation of cancer incidence rates coupled with inadequate funding for health expenses in some countries could have grim consequences in the near future. 
Cancer risk varies geographically, leading to a substantial variation across native and immigrant populations. ${ }^{18} \mathrm{Immi}-$ gration rates differ between Western and Eastern parts of Europe considerably and are generally low in Hungary and in other Central and Eastern European countries as well. Studies on migration indicate that cancer rates among migrants and their descendants approach prevailing rates in the host country after they adopt the native lifestyle habits, including smoking, diet, and reproductive behaviors. ${ }^{19}$ Taking into account the generally low migration rate in Hungary, we did not include migration in our model as an independent factor.

Currently, the lifetime probability of developing cancer in Hungary is $56.9 \%$ in men and $51.9 \%$ in women. The cancer burden of Hungary is still growing - by 2030 the population is projected to shrink by $6 \%$, yet an approximately $35 \%$ increase in cancer incidence and $30 \%$ in cancer-related mortality are expected among those $65-85$ years old. Improving treatment may also result in increased cancer prevalence, as cancer patients may live longer with their disease. The prospective increase in extended cancer care may impose additional challenges on the health care system.

While ASRs of male cancer incidence and mortality are declining, female ASRs for both incidence and mortality show a rising trend. Of note, incidence and mortality trends do not necessarily reflect each other, especially in certain cancers with typically high cure rates, such as melanoma and prostate cancer. In cancers with a worse prognosis, such as pancreatic cancer, incidence and mortality are more closely associated.

Between 2001 and 2015, four cancer sites, the lung, colon, breast, and prostate, accounted for most new cases diagnosed. In Europe, among the 11 most common cancers, almost twothird are reported to be hypothetically preventable. ${ }^{20}$ When adjusting these tumor types to sex and incidence, a stunning $77 \%$ of the cancer incidence in Hungarian men is made up of preventable malignancies.

Tobacco use is one of the major causes of preventable deaths. ${ }^{21}$ In addition to being responsible for approximately $87-91 \%$ of lung cancers in men and $57-86 \%$ in women, ${ }^{22-24}$ smoking has been linked to a dozen other cancers, including CRC and cancers of the pancreas, oral cavity and pharynx, bladder, and kidney. Although anti-smoking efforts achieved a fall in both smoking-related lung cancer incidence and mortality among men in the last two decades, ${ }^{25}$ smoking prevalence remains at $28 \%$ in Europe. ${ }^{26}$ Among Hungarian men, the extent of tobacco use started a steep decline in the 1990 s, leading to a constant decrease in tobacco-related malignancies. This development will still lead to appreciable reduction of cancers of the lung, oral cavity, larynx, and esophagus in the future (Figure 4B). However, the proportion of daily smokers has been increasing among women in Central and Eastern Europe. ${ }^{27}$ Overall, lung cancer mortality in 2002-2012 in the Europe has increased by $17.5 \%$ among women. ${ }^{28}$ According to a 2014 survey, $29 \%$ of the Hungarian population smoked, $28 \%$ of those regularly, and the prevalence of smoking increased among those aged 18-34 years. Among men, $42 \%$ of young adults (18-34 years of age) and $35 \%$ in middle age were smoking, while $29 \%$ and $27 \%$ of 18-34-year-old and 35-65-year-old women were smokers, respectively (Central Statistical Office of Hungary). ${ }^{29}$ The soaring trends among young adults urge the resumption of anti-smoking campaigns aimed at vulnerable age groups.

The ASRs suggest an overall decline in both the incidence and mortality of stomach cancer among men and women. The pattern is comparable to steady decline of stomach cancer incidence and mortality of the past 40 years observed in Nordic countries (Finland, Denmark, Iceland, Norway, and Sweden) - the cause of this decline is still not fully understood. ${ }^{30}$ Nevertheless, crude rates provide the maximum information for local health legislation, and particularly among Hungarian men, crude rates of stomach cancer are predicted to remain on a moderately increasing trend.

The European incidence of CRC is highest in the former Czechoslovakia and Hungary. ${ }^{3,31}$ In Hungary, the incidence of $\mathrm{CRC}$ is increasing and is projected to surpass LC. Mortality rates are predicted to rise at an even more alarming pace, especially among women and older generations. Although CRC may be asymptomatic for a long time, a third of mortality could be preventable by adopting the annual fecal occultblood testing. ${ }^{32}$ Currently, of the 19 regions in Hungary, only four participate in an experimental model of biennial CRC screening, clearly insufficient to trigger a substantial change in the entire population. A chemo-preventive alternative would be the introduction of recommendations published by the US Preventive Services Task Force in 2015. In USA, regular use of aspirin has been described as a promising tool in CRC prevention when used in low daily doses for 10 years or longer in adults 50-59 years, and it may also be potentially effective among 60-69-year olds. ${ }^{33}$

Alcohol consumption has been directly linked to the development of colorectal, oral cavity and pharynx, esophageal, liver, and female breast cancers, ${ }^{34}$ and up to $9 \%$ of cancer incidence is the result of excess alcohol consumption in Europe.$^{27}$ Excessive drinking habits can predestine a population to a high occurrence of alcohol-related cancers. People in Central and Eastern Europe, and particularly in Hungary, drink more alcohol per capita compared to the 
rest of Europe, and among women, the highest proportion of alcohol consumption has been recorded in Hungary. ${ }^{35}$

High body mass index (BMI), defined by WHO as BMI $>25 \mathrm{~kg} / \mathrm{m}^{2}$, is associated with increased risk of cancer and continues to rise all across Europe. ${ }^{27}$ The prevalence of overweight and obesity is increasing in Hungary: according to a 2014 study, $40.4 \%$ of adult males and $31.3 \%$ of females were overweight. Moreover, $32 \%$ of men and $31.5 \%$ of women were obese, and one-third of young men under 35 years of age already carried excess weight. ${ }^{36}$ Investigating 30 European countries, $2.5 \%$ of men and $4.1 \%$ of women cancer cases were attributable to excess BMI, mainly endometrial, breast, and colorectal cancers. ${ }^{37}$ Strong associations have also been found between high BMI and the risks of renal, esophageal adenocarcinoma, and thyroid cancers in men and esophageal adenocarcinoma, renal, and gallbladder cancers in women. ${ }^{38}$

Strikingly, upgrading the European reference population from the 1976 ESP to the most recent 2013 ESP increased ASRs dramatically, to up to $68 \%$. Thus, many cancer cases were hidden due to the utilization of an outdated reference population. Moreover, the difference in almost all cancer types warns against the extrapolation of USA-based cancer epidemiology data to other countries, as the demographic difference renders USA data unreliable for Europe. Each country, or at least each continental region, should employ an updated reference population to better estimate the number of cases.

\section{Limitation}

A limitation of our study is the relative short follow-up compared, especially, to that from Nordic countries, where the follow-up started over 70 years ago (e.g., the Danish Cancer Registry was founded in 1942). ${ }^{39}$ However, despite this limitation, our study is the first to provide a comprehensive survey and prediction for the next 15 years by incorporating data obtained from different sources.

\section{Conclusion}

In summary, we present a state-of-the-art snapshot of cancer morbidity and mortality in Hungary. We corrected for biases that were present in previous analyses, including the inappropriate reference population and unsuitable standardizations. The updated demographic trends forecast a significant increase in crude rates of cancer incidence over the next 15 years in Hungary. Our corrected estimates of cancer burden show the need for immediate and intensive prevention programs and targeted anticancer actions. Our projections may be suitably extrapolated to countries with similar predicaments in economics, demography, and cancer burden.

\section{Acknowledgment}

This work was supported by the National Research, Development and Innovation Office (Nemzeti Kutatási, Fejlesztési és Innovációs Hivatal), Hungary (grant number NVKP_16-1-2016-0037).

\section{Disclosure}

The authors report no conflicts of interest in this work.

\section{References}

1. United Nations, DESA/Populations Division. World Population Prospects: the 2015 Revision. Available from: https://esa.un.org/unpd/wpp/ Publications/.2015. Accessed February 1, 2017.

2. Ferlay J, Soerjomataram I, Dikshit R, et al. Cancer incidence and mortality worldwide: sources, methods and major patterns in GLOBOCAN 2012. Int J Cancer. 2015;136(5):E359-E386.

3. Ferlay J, Steliarova-Foucher E, Lortet-Tieulent J, et al. Cancer incidence and mortality patterns in Europe: estimates for 40 countries in 2012. Eur J Cancer. 2013;49(6):1374-1403.

4. Dusek L, Muzik J, Maluskova D, et al. Cancer incidence and mortality in the Czech Republic. Klin Onkol. 2014;27(6):406-423.

5. Turnbull A, Osborn M, Nicholas N. Hospital autopsy: endangered or extinct? J Clin Pathol. 2015:68(8):601-604.

6. Eurostat. Revision of the European Standard Population. Report of Eurostat's task force. Luxembourgh: Publications Office of the European Union; 2013.

7. World Health Organization. ICD-10: international statistical classification of diseases and related health problems: tenth revision. 2 nd ed. Geneva: World Health Organization. Available from: http://www.who. int/iris/handle/10665/42980. Accessed February 1, 2017.

8. Møller B, Fekjaer H, Hakulinen T, et al. Prediction of cancer incidence in the Nordic countries: empirical comparison of different approaches. Stat Med. 2003;22(17):2751-2766.

9. Holford TR. The estimation of age, period and cohort effects for vital rates. Biometrics. 1983;39(2):311-324.

10. Møller B, Weedon-Fekjær H, Haldorsen, T. Empirical evaluation of prediction intervals for cancer incidence. BMC Med Res Methodol. 2005;5:21.

11. Furukawa T, Fujisaki R, Yoshida Y, et al. Distinct progression pathways involving the dysfunction of DUSP6/MKP-3 in pancreatic intraepithelial neoplasia and intraductal papillary-mucinous neoplasms of the pancreas. Mod Pathol. 2005;18(8):1034-1042.

12. Kim HJ, Fay MP, Feuer EJ, Midthune DN. Permutation tests for joinpoint regression with applications to cancer rates. Stat Med. 2000;19(3): 335-351.

13. Martin-Castillo $\mathrm{B}$, Lopez-Bonet $\mathrm{E}$, Cuyàs $\mathrm{E}$, et al. Cancer stem celldriven efficacy of trastuzumab (Herceptin): towards a reclassification of clinically HER2-positive breast carcinomas. Oncotarget. 2015;6(32): 32317-32338.

14. Fay MP, Pfeiffer R, Cronin KA, Le C, Feuer EJ. Age-conditional probabilities of developing cancer. Stat Med. 2003;22(11):1837-1848.

15. Fay MP. Estimating age conditional probability of developing disease from surveillance data. Popul Health Metr. 2004;2(1):6.

16. Siegel RL, Miller KD, Jemal A. Cancer statistics, 2016. CA Cancer J Clin. 2016;66(1):7-30.

17. Jönsson B, Hofmarcher T, Lindgren P, Wilking N. The cost and burden of cancer in the European Union 1995-2014. Eur J Cancer. 2016;66:162-170. 
18. Arnold M, Razum O, Coebergh JW. Cancer risk diversity in non-western migrants to Europe: an overview of the literature. Eur J Cancer. 2010;46(14):2647-2659.

19. Stanford JL, Herrinton LJ, Schwartz SM, Weiss NS. Breast cancer incidence in Asian migrants to the United States and their descendants. Epidemiology. 1995:6(2):181-183.

20. Soerjomataram I, de Vries E, Pukkala E, Coebergh JW. Excess of cancers in Europe: a study of eleven major cancers amenable to lifestyle change. Int J Cancer. 2007;120(6):1336-1343.

21. WHO. IARC monographs on the evaluation of carcinogenic risk to humans. Tobacco smoke and involuntary smoking. Lyon, France: International Agency for Research on Cancer; 2004. Available from: https:// www.ncbi.nlm.nih.gov/books/NBK316407/. Accessed February 1, 2017.

22. Parkin DM, Pisani P, Lopez AD, Masuyer E. At least one in seven cases of cancer is caused by smoking. Global estimates for 1985. Int J Cancer. 1994;59(4):494-504.

23. Olsen JH, Andersen A, Dreyer L, et al. Summary of avoidable cancers in the Nordic countries. APMIS Suppl. 1997;76:141-146.

24. Dela Cruz CS, Tanoue LT, Matthay RA. Lung cancer: epidemiology, etiology, and prevention. Clin Chest Med. 2011;32(4):605-644.

25. Malvezzi M, Bosetti C, Rosso T, et al. Lung cancer mortality in European men: trends and predictions. Lung Cancer. 2013;80(2):138-145.

26. WHO. World Health Organization: Tobacco Fact Sheet; 2014. Available from: http://www.wpro.who.int/mediacentre/factsheets/fs_201203_ tobacco/en/. Accessed February 1, 2017.

27. Martin-Moreno JM, Soerjomataram I, Magnusson G. Cancer causes and prevention: a condensed appraisal in Europe in 2008. Eur J Cancer. 2008;44(10):1390-1403.

28. Malhotra J, Malvezzi M, Negri E, La Vecchia C, Boffetta P. Risk factors for lung cancer worldwide. Eur Respir J. 2016;48(3):889-902.
29. Monostori J, Öri P, Spéder Z, editors: Demográfiai portré 2015 [Demographic portrait 2015]. Budapest: KSH NKI; 2015.

30. Klint A, Engholm G, Storm HH, et al. Trends in survival of patients diagnosed with cancer of the digestive organs in the Nordic countries 19642003 followed up to the end of 2006. Acta Oncol. 2010;49(5):578-607.

31. Plesko I, Boyle GS, Ondrusova M, Tomasek L, Kubik A. Dominant position of colorectal cancer in Slovakia: the old-new problem for cancer control. Neoplasma. 2008;55(1):10-15.

32. Mandel JS, Bond JH, Church TR, et al. Reducing mortality from colorectal cancer by screening for fecal occult blood. $N$ Engl J Med. 1993;328(19):1365-1371.

33. Louis DN, Ohgaki H, Wiestler OD, et al. The 2007 WHO classification of tumours of the central nervous system. Acta Neuropathol. 2007;114(2): 97-109.

34. Rehm J, Baliunas D, Borges GL, et al. The relation between different dimensions of alcohol consumption and burden of disease: an overview. Addiction. 2010;105(5):817-843.

35. Popova S, Rehm J, Patra J, Zatonski W. Comparing alcohol consumption in central and eastern Europe to other European countries. Alcohol Alcohol. 2007;42(5):465-473.

36. Rurik I, Torzsa P, Szidor J, et al. A public health threat in Hungary: obesity, 2013. BMC Public Health. 2014;14:798.

37. Renehan AG, Soerjomataram I, Tyson M, et al. Incident cancer burden attributable to excess body mass index in 30 European countries. Int $J$ Cancer. 2010;126(3):692-702.

38. Renehan AG, Tyson M, Egger M, Heller RF, Zwahlen M. Body-mass index and incidence of cancer: a systematic review and meta-analysis of prospective observational studies. Lancet. 2008;371(9612):569-578.

39. Engholm G, Ferlay J, Christensen N, et al. NORDCAN - a Nordic tool for cancer information, planning, quality control and research. Acta Oncol. 2010;49(5):725-736.
Clinical Epidemiology

\section{Publish your work in this journal}

Clinical Epidemiology is an international, peer-reviewed, open access, online journal focusing on disease and drug epidemiology, identification of risk factors and screening procedures to develop optimal preventative initiatives and programs. Specific topics include: diagnosis, prognosis, treatment, screening, prevention, risk factor modification,

Submit your manuscript here: https://www.dovepress.com/clinical-epidemiology-journa

\section{Dovepress}

systematic reviews, risk and safety of medical interventions, epidemiology and biostatistical methods, and evaluation of guidelines, translationa medicine, health policies and economic evaluations. The manuscrip management system is completely online and includes a very quick and fair peer-review system, which is all easy to use. 